\title{
Aloe vera and Vitis vinifera improve wound healing in an in vivo rat burn wound model
}

\author{
LI-XIN LIN* ${ }^{*}$ PENG WANG* ${ }^{*}$, YU-TING WANG, YONG HUANG, LEI JIANG and XUE-MING WANG \\ Department of Plastic and Aesthetic Center, Yantai Yuhuangding Hospital, Yantai, Shandong 264000, P.R. China
}

Received October 11, 2014; Accepted July 28, 2015

DOI: $10.3892 / \mathrm{mmr} .2015 .4681$

\begin{abstract}
Aloe vera and Vitis vinifera have been traditionally used as wound healing agents. The present study aimed to investigate the effects of aloe emodin and resveratrol in the burn wound healing procedure. Burn wounds are common in developed and developing countries, however, in developing countries, the incidence of severe complications is higher and financial resources are limited. The results of the present study demonstrated that neither aloe emodin or resveratrol were cytotoxic to THP-1 macrophages at concentrations of 1 , 100 and $500 \mathrm{ng} / \mathrm{ml}$. A significant increase in wound-healing activity was observed in mice treated with the aloe emodin and resveratrol, compared with those which received control treatments. The levels of IL-1 $\beta$ in the exudates of the burn wound area of the treated mice increased in a time-dependent manner over 7 days following burn wound injury. At 10 days post-injury, steady and progressive wound healing was observed in the control animals. The present study confirmed that increased wound healing occurs following treatment with aloe emodin,, compared with resveratrol, providing support for the use of Aloe vera plants to improve burn wound healing.
\end{abstract}

\section{Introduction}

The skin can damaged due to burn injuries, chronic wounds, skin excision, tumours or other dermatological conditions (1). For the repair and regeneration of damaged tissue, a continuous cascade of events occurs, which involves the interaction of cellular components, growth factors and cytokines within four sequential and overlapping phases, including haemostasis, inflammation, proliferation and tissue remodelling or maturation $(2,3)$.

Correspondence to: Dr Xue-Ming Wang, Department of Plastic and Aesthetic Center, Yantai Yuhuangding Hospital, 20 East Yuhuangding Road, Yantai, Shandong 264000, P.R. China

E-mail: wangxueming601@gmail.com

\section{${ }^{*}$ Contributed equally}

Key words: aloe-emodin, resveratrol, THP-1 cell lines, interleukin-1 $\beta$, vascular endothelial growth factor
The Aloe vera plant has long been used in medicine, as a dietary supplement and for cosmetic purposes (4). Aloe vera extracts are a rich source of polyphenols, including aloin and aloe emodin, and exhibit a wide range of pharmacological properties, including anti-inflammatory and anti-cancer properties (5). The claimed therapeutic uses of Aloe vera range over a broad list of conditions, as do its associated pharmacological activities. The majority of these claims are based on historical use, rather than scientific evidence. Different sections of the plant are used in the traditional management of veterinary and human diseases (6). Aloe vera is the most biologically active of the Aloe species, and is composed of $>70$ active compounds, including vitamins, minerals, amino acids, anthraquinones, enzymes and salicylic acids (7). The beneficial properties of the plant are ascribed to the colourless leaf gel, which has been reported to stimulate wound-healing and skin hydration, induce hematopoiesis, antimicrobial and anti-inflammatory activities (8-10). The pharmacological properties of Aloe vera appear to be mediated predominantly by the activation of monocytes and macrophages, and extracts of Aloe vera have been reported to enhance the release of cytokines, including interleukin (IL)-1, IL-2, IL-6, interferon, granulocyte/monocyte-colony stimulating factor and tumor necrosis factor (TNF) in vitro (11). Oryan et al (12) reported that Aloe vera aqueous extract may be used as a promising medication for wound healing.

The common grape (Vitis vinifera $\mathrm{L}$. Vitaceae) is regarded as an important medicinal plant. European doctors have suggested the use of grapevine sap, juice and whole grape in the treatment of pain, allergic reactions, inflammation and to promote wound healing $(13,14)$. Resveratrol (trans-3,4, 5-trihydroxystillbene), a phytoalexin that belongs to a group of compounds termed stilbenes, is found in dietary items, including red wine, grapes and peanuts (15). It has been demonstrated that resveratrol confers several beneficial effects in human and animal models, and is being investigated as a chemopreventative agent for cancer and cardiovascular disease, most likely due to its antioxidative and anti-proliferative activities $(16,17)$. IL-1 $\beta$ functions as a 'master' cytokine, which has an indispensable role in orchestrating effective innate and adaptive immune responses (18).

In the present study, the burn wound healing properties of aloe emodin (Aloe vera) and resveratrol (Vitis vinifera) were investigated using in vitro and in vivo methods, in order to identify the clinical effects of the two compounds. 


\section{Materials and methods}

Materials. Resveratrol was isolated, as previously described by Park et al (19). Aloe emodin was purchased from Sigma-Aldrich (St. Louis, MO, USA). Dulbecco's modified Eagle's medium and RPMI-1640 medium were purchased from Sigma-Aldrich and used as a culture media. A 100X antibiotic and antimycotic solution containing 10,000 U/ml penicillin, $10 \mathrm{mg} / \mathrm{ml}$ streptomycin and $25 \mu \mathrm{g} / \mathrm{ml}$ amphotericin $\mathrm{B}$ in $0.9 \% \mathrm{NaCl}$, was purchased from Sigma-Aldrich. Multi-well plates (6-, 12- or 48-well) were purchased from Corning Incorporated (Corning, NY, USA). Human and murine vascular endothelial growth factor (VEGF), murine IL-1 $\beta$ and murine monocyte chemoattractant protein-1 (MCP-1) ELISA kits were obtained from Cusabio Biotech Co., Ltd. (Wuhan, China). An ImmunoCruz ${ }^{\mathrm{TM}}$ staining kit for the detection of murine VEGF was purchased from Santa Cruz Biotechnology, Inc. (Dallas, TX, USA). Rat monoclonal anti-mouse MCP 1 (clone ECE.2; cat. no. CLYPAR-100-MCP1) (CCL2/MCP1 antibody was raised against synthetic peptide corresponding to residues 102-130 of mouse MCP-1 specific to mouse CCR2), rat monoclonal anti-mouse macrophage (clone BM8; cat. no. T-2028) (BM8 monoclonal antibody reacts with mouse F4/80 antigen specific to mouse and rat) and rabbit polyclonal anti-myeloperoxidase antibodies (cat. no. P05164) (rabbit polyclonal to myeloperoxidase raised from human granulocytes reacts specific to mouse, rat, human, pig and monkey) were purchased from Sanbio BV (Uden, Netherlands), BMA Biomedicals (Augst, Switzerland), and Thermo Fisher Scientific, Inc. (Waltham, MA, USA), respectively.

Cells. The THP-1 human acute monocytic leukemia and $\mathrm{HaCaT}$ human keratinocyte cell lines (American Type Culture Collection, Rockville, MD, USA) were and maintained in RPMI-1640 medium supplemented with $10 \%$ fetal bovine serum (Sigma-Aldrich), penicillin $(100 \mathrm{U} / \mathrm{ml})$, streptomycin $(100 \mu \mathrm{g} / \mathrm{ml})$ and amphotericin $(0.25 \mu \mathrm{g} / \mathrm{ml})$. The plates were incubated overnight for 12 or $72 \mathrm{~h}$.

Animals. Male BALB/c mice (5-week-old, $\mathrm{n}=30$ ) were obtained from ShanDong University (Jinan China) and housed one per cage (to prevent attacks on wounds) for 1 week in a temperature-controlled room at $25 \pm 1^{\circ} \mathrm{C}$ with $60 \%$ relative humidity and a 12-h light-dark cycle, and provided with access to a standard laboratory diet and water ad libitum prior to experimentation. The ethical guidelines of the Animal Center of Yantai Yuhuangding Hospital, Yantai, Shandong Province, China. The mice were treated according to the ethical guidelines of the Animal Center of Yantai Yuhuangding Hospital (Yantai, China), and the Animal Studies Committee of the Shan Dong University approved all experimental procedures.

Cell proliferation determination using MTT assays. Following treatment with different concentrations of aloe emodin (1, 100 and $500 \mathrm{ng} / \mathrm{ml}$ ) for $24 \mathrm{~h}$, the cells were washed with phosphate-buffered saline (PBS; $\mathrm{pH}$ 7.2) and incubated in fresh medium for 4 days. The number of surviving cells was then indirectly determined using an MTT cytotoxicity assay (Sigma-Aldrich), according to the manufacturer's instructions. The absorbance was measured using a Multiskan EX ELISA plate reader (MTX Lab Systems, Inc., Vienna, VA, USA) at a wavelength of $570 \mathrm{~nm}$, with a reference wavelength of $650 \mathrm{~nm}(20,21)$.

Measurement of burn wound healing. To examine the effects of aloe emodin and isolated resveratrol on the burn wound healing process, burn wounds were created on the backs of male $\mathrm{BALB} / \mathrm{c}$ mice following anesthetization with an intraperitoneal injection of pentobarbital $(50 \mu \mathrm{g} / \mathrm{g}$; Hubei Nosk Chemical Co., Ltd., Hubei, China). Briefly, the hair on the backs of the mice was removed using a hair remover (Xiantao Topmed Nonwoven Protective Products, Co. Ltd., Hubei, China) under anaesthesia with pentobarbital, and the back was subsequently wiped with distilled water warmed to $37^{\circ} \mathrm{C}$, followed by $70 \%$ ethanol. The back skin was subjected with a $100^{\circ} \mathrm{C}$ custom-made soldering iron tip (Shenzhen Kingdom Technology Co., Ltd. Guangdong, China) for $10 \mathrm{sec}$. A full-thickness excision of the burn skin wound was made in the dorsal skin by lifting a fold of skin at the midline and punching through two layers of skin using a sterile disposable biopsy punch (diameter $8 \mathrm{~mm}$ ) on the same day. The mice were housed separately and provided with free access to a standard laboratory diet and water following the completion of the surgical procedure. Subsequently, the indicated quantities (100 mg ointment/mouse) of resveratrol $\left[2 \times 10^{-4}\right.$ and $\left.5 \times 10^{-4} \%(\mathrm{w} / \mathrm{w})\right]$ and aloe-emodin $\left[1 \times 10^{-8}, 1 \times 10^{-10}\right.$ and $\left.1 \times 10^{-12} \%(\mathrm{w} / \mathrm{w})\right]$ were layered on the burn wound surface for 19 consecutive days and covered with Opsite Flexigrid film dressing (Smith \& Nephew, London, UK) to prevent infection or licking of the ointment samples. Clear Vaseline alone was applied to the control burn wound mice. On day 20, the mice were sacrificed by cervical dislocation and the skin of the wound area was removed. In the experiment of the effects of resveratrol on burn wound healing, a vehicle control group, which received treatment with clear Vaseline alone, and two treatment groups, treated with ointment containing $2 \times 10^{-4}$ or $5 \times 10^{-4} \%(\mathrm{w} / \mathrm{w})$ aloe emodin ( $\mathrm{n}=3$ per group) were compared. In the experiments examining the effects of resveratrol, the number of animals in each treatment group were as follows: A vehicle control group treated with clear Vaseline alone $(n=11)$; a $1 \times 10^{-8} \%(\mathrm{w} / \mathrm{w})$ aloe emodin-treated group $(\mathrm{n}=11)$; a $1 \times 10^{-10}$ $(\mathrm{w} / \mathrm{w})$ aloe emodin-treated group $(\mathrm{n}=7)$; and a $1 \times 10^{-12} \%(\mathrm{w} / \mathrm{w})$ aloe emodin-treated group $(n=7)$. The above topical applications were performed under anaesthesia with pentobarbital.

Assessment of polymorphonuclear neutrophil levels. The backs of the mice were subjected to burn wounds using the same method as described above. A polyethylene filter pellet ( $\sim 6 \mathrm{~mm}$ diameter; $2 \mathrm{~mm}$ thickness; Hebei Yuyin Trade Co., Ltd., Hebei, China) containing the above-mentioned quantities of aloe emodin and resveratrol was applied to the burn wound surface and covered with Opsite Flexigrid film dressing to prevent dislodging of the filter pellet. The filter pellets were removed after 1, 3, 5 and 7 days and replaced with fresh filter pellets. The control mice were treated with filter pellets containing $0.9 \%$ (isotonic) $\mathrm{NaCl}$ solution alone at the same time-points. On day 9, the mice were sacrificed and the filter pellets were removed prior to the addition of $200 \mu \mathrm{l}$ PBS ( $\mathrm{pH}$ 7.0) to the filter pellets. The solution was mixed for $10 \mathrm{~min}$ using a Vortex (vortex mixer-V8, 200-3,000 rpm/min; Seoulin Bioscience, Seoul, Korea). Following removal of the filter pellet, the mixture was centrifuged at $1,000 \mathrm{x} \mathrm{g}$ for 
10 min at $4^{\circ} \mathrm{C}$. The obtained cell pellets were resuspended in PBS.

The total number of leukocytes, including polymorphonuclear leukocytes and macrophages, were measured using a Vi-CELL XR Coulter cell counter (Beckman Coulter Inc., Brea, CA, USA), and the ratio of polymorphonuclear leukocytes to macrophages was determined using Giemsa-stained smear samples. Briefly, the blood samples were placed on clean slides, air dried, fixed in methanol and stained with Giemsa (SigmaAldrich). They were then observed under x100 magnification.

Measurement of cytokine levels in burn wounds. For this assessment, seven mice were used for each treatment group, which consisted of a vehicle control group treated with $0.9 \%$ $\mathrm{NaCl}$ solution alone, and 1,100, and $500 \mathrm{ng}$ aloe emodin and resveratrol-treated groups. These experiments were also performed under anaesthesia with pentobarbital. Briefly, $100 \mathrm{mg}$ tissue was rinsed with $1 \mathrm{X}$ PBS, homogenized in $1 \mathrm{ml}$ of $1 \mathrm{X}$ PBS and stored overnight at $-20^{\circ} \mathrm{C}$. Two freeze-thaw cycles were then performed to break the cell membranes, and the homogenates were centrifuged for $5 \mathrm{~min}$ at $5,000 \mathrm{xg}$ and $2-8^{\circ} \mathrm{C}$. The supernatant was removed and assayed immediately. The expression levels of MCP-1, IL-1 $\beta$ and VEGF in the filter pellets were measured using mouse MCP-1, IL-1 $\beta$ and VEGF ELISA kits (BD Biosciences, Franklin Lakes, NJ, USA), according to the manufacturer's instructions. The readings were taken at $450 \mathrm{~nm}$ using an ELISA reader (Thermo Fisher Scientific, Inc.).

Wound analysis. Wound closure rate was assessed by tracing the wound $1,2,4,8,16$ and 20 days post-wounding using transparency paper and a permanent marker. The time to wound closure was defined as the time-point at which the wound bed was completely re-epithelialised with new tissue. The wound area was measured by tracing the wound margin, and its surface area was calculated using Image $\mathbf{J}$ software (National Institutes of Health, Bethesda, MA, USA). The wound area was visually measured using an Lx400 microscope (Labomed, Fremont, CA, USA) at X10 magnification. The wound healing rate was calculated using the following formula: (Surface area of the original wound - surface area of the remaining wound) / surface area of the original wound $\mathrm{x} 100$.

Histopathological analysis. On days 4 and 10 of experimentation, seven mice were sacrificed from each group were sacrificed and the wounds were excised, together with the surrounding skin. The tissue samples were fixed in 10\% neutral-buffered formalin (Shijiazhuang Xinlong wei Chemical Co., Ltd., Hebei, China) for at least $24 \mathrm{~h}$, progressively dehydrated in solutions containing an increasing percentage of ethanol (70, 80, 95 and $100 \%$ ), cleared in Histoclear (AS ONE Corp., Tokyo, Japan), embedded in paraffin (Raylabel Instrument Co., Ltd., Shanghai, China) under vacuum, sectioned $(5 \mu \mathrm{m})$, de-paraffinised and stained with hematoxylin and eosin (Beijing Tidybio Science $\&$ Technology Co., Ltd., Beijing, China). The stained sections were examined for collagen, inflammatory cells and blood vessel markers of healing.

Statistical analysis. The data are expressed as the mean \pm standard error of the mean. The results were analysed
A<smiles>O=C1c2cccc(O)c2C(=O)c2c(O)cc(CO)cc21</smiles>

B

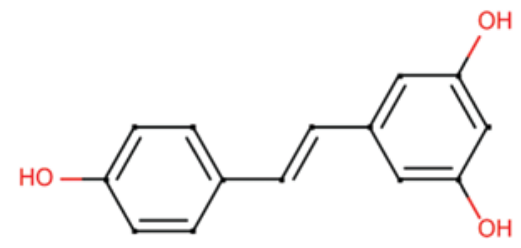

Figure 1. Molecular structures of (A) aloe emodin. (B) resveratrol.

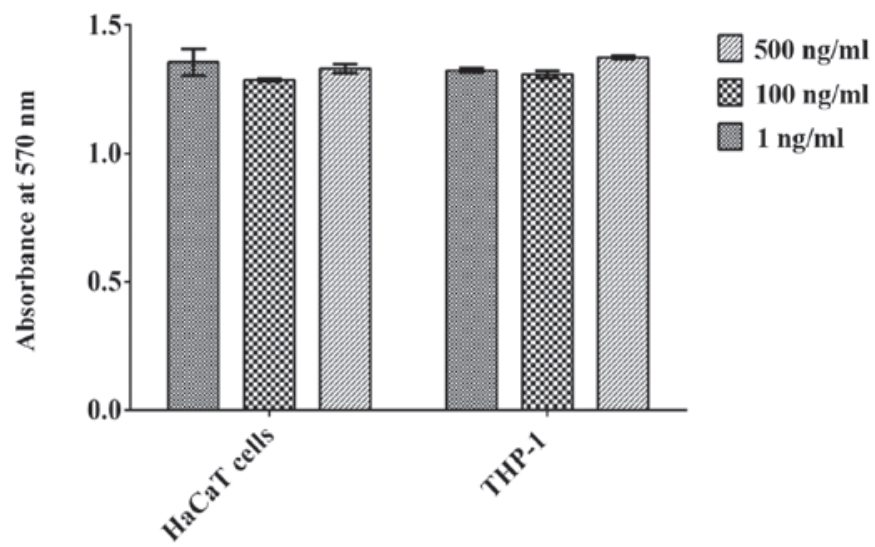

Figure 2. Cell proliferation of aloe emodin and resveratrol-treated HaCaT and THP-1 cells, determined using an MTT assay. Data are presented as the mean \pm standard error of the mean. Neither compound exhibited cytotoxicity towards either cell line. $(\mathrm{P}>0.005)$.

using one-way analysis of variance and Dunnett's multiple comparison test. Statistical analyses were performed using SPSS software version 16.0 (SPSS Inc., Chicago, IL, USA). $\mathrm{P}<0.05$ was considered to indicate a statistically significant difference.

\section{Results}

Cell proliferation assay. The molecular structures of aloe emodin and resveratrol were similar to those reported previously (Fig. 1A and B). Treatment with either aloe emodin or resveratrol did not result in cytotoxicity in either the $\mathrm{HaCaT}$ cells or THP-1 macrophages at concentrations of 1,100 and $500 \mathrm{ng} / \mathrm{ml}$ (Fig. 2). Furthermore, aloe emodin and resveratrol had no effect on the proliferation of the HaCaT cells or THP-1 macrophages.

Wound healing. Wound healing rates were measured on different days following wounding. In all groups, wound healing rates increased with increasing duration. Significant increases in wound-healing activity were observed in the mice treated with aloe emodin and resveratrol, compared with those 
Table I. Effects of aloe emodin and resveratrol on the levels of VEGF and MCP-1 in cultured HaCaT cells in vitro.

\begin{tabular}{lcc}
\hline Treatment (ng/ml) & VEGF (ng/well) $^{\mathrm{a}}$ & MCP-1 (ng/well) $^{\mathrm{a}}$ \\
\hline Medium alone & $87.32 \pm 7.47$ & $2.471 \pm 0.241$ \\
Aloe emodin & & \\
1 & $96.18 \pm 8.46$ & $3.341 \pm 0.345^{\mathrm{b}}$ \\
100 & $92.26 \pm 6.25$ & $3.333 \pm 0.431^{\mathrm{b}}$ \\
500 & $97.40 \pm 6.21$ & $3.697 \pm 0.143^{\mathrm{b}}$ \\
Medium alone & $84.62 \pm 2.67$ & $2.562 \pm 0.533$ \\
Resveratrol & & \\
1 & $93.13 \pm 7.35$ & $3.332 \pm 0.842^{\mathrm{b}}$ \\
100 & $92.23 \pm 6.63$ & $3.652 \pm 0.435^{\mathrm{b}}$ \\
500 & $97.36 \pm 6.35$ & $3.637 \pm 0.144^{\mathrm{b}}$ \\
\hline
\end{tabular}

aalues are presented as the mean \pm standard error of the mean of six experiments. ${ }^{b} \mathrm{P}<0.05$, vs. medium alone. VEGF, vascular endothelial growth factor; MCP-1, monocyte chemoattractant protein-1.

Table II. Effects of treatment with aloe emodin and resveratrol on the epithelialization of the burn wounds in mice.

\begin{tabular}{lcc}
\hline Group & $\begin{array}{c}\text { Time to } \\
\text { decrustation }\end{array}$ & $\begin{array}{c}\text { Healing } \\
\text { time }^{\mathrm{b}} \text { (days) }\end{array}$ \\
\hline Control & $9.80 \pm 1.56$ & $21.89 \pm 2.36$ \\
Aloe emodin & $7.24 \pm 1.45^{\mathrm{a}}$ & $17.20 \pm 4.35^{\mathrm{a}}$ \\
Resveratrol & $10.05 \pm 5.23$ & $19.10 \pm 2.57^{\mathrm{a}}$ \\
\hline
\end{tabular}

Values are presented as the mean \pm standard error of the mean of six experiments. $\mathrm{P}<0.05$, vs. control group. ${ }^{\mathrm{T}}$ The appearance of an eschar. ${ }^{\mathrm{b}}$ Rate of wound closure.

that received control treatments. The effects of the treatments on the wound-healing activity levels in mice with excision wounds are presented in Tables I and II. In this model, the aloe emodin-treated mice exhibited a significant increase in wound healing rate $(\mathrm{P}<0.05)$, and a decreased time to epithelialization, compared with the control mice.

Effects of aloe emodin and resveratrol on burn wound healing in mice. The wound injury area created by an iron bar heated at $100^{\circ} \mathrm{C}$ reached a maximum on days $6-8$, and wound repair was subsequently observed. The burn wound area in the groups treated with the topical application of resveratrol at doses of $2 \times 10^{-4}$ and $5 \times 10^{-4} \%(\mathrm{w} / \mathrm{w})$ decreased on days 8 and 19, compared with those in the vehicle-treated control mice (Fig. 3A-C). Previous studies have investigated the effect of natural products isolated from medicinal plants on skin regeneration in burn wound healing (22). The present study also demonstrated that the burn wound areas in mice treated with aloe emodin and resveratrol at doses of $1 \times 10^{-8}$ and $1 \times 10^{-12} \%$ were significantly $(\mathrm{P}<0.05)$ reduced after 6-18 days, compared with those of the control group, however, no significant difference was observed between the non-control treatment groups (Fig. 4A and B).

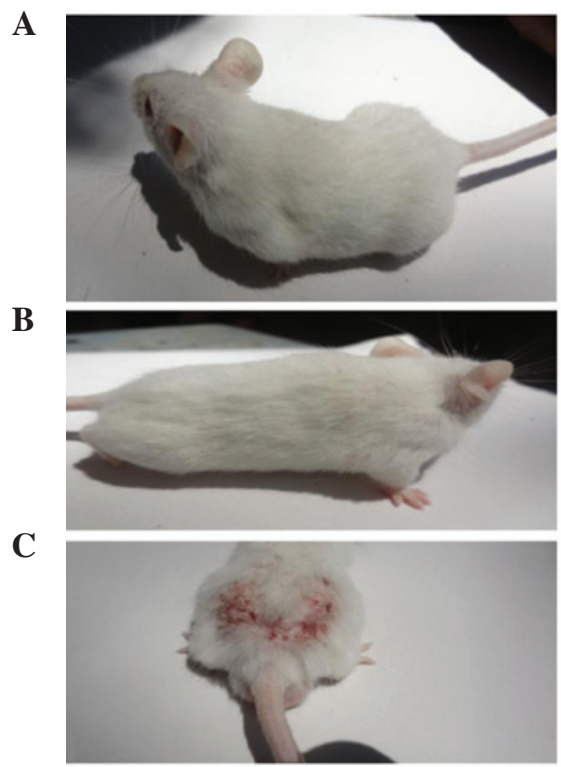

Figure 3. Images of wound healing. Representative images of mice in the (A) control group and the groups treated with (B) $500 \mathrm{ng}$ aloe emodin ointment and (C) $500 \mathrm{ng}$ resveratrol. Wound healing was incomplete in the mice treated with resveratrol, in which marginal healing and scarce hair follicle formation was observed after 19 days.

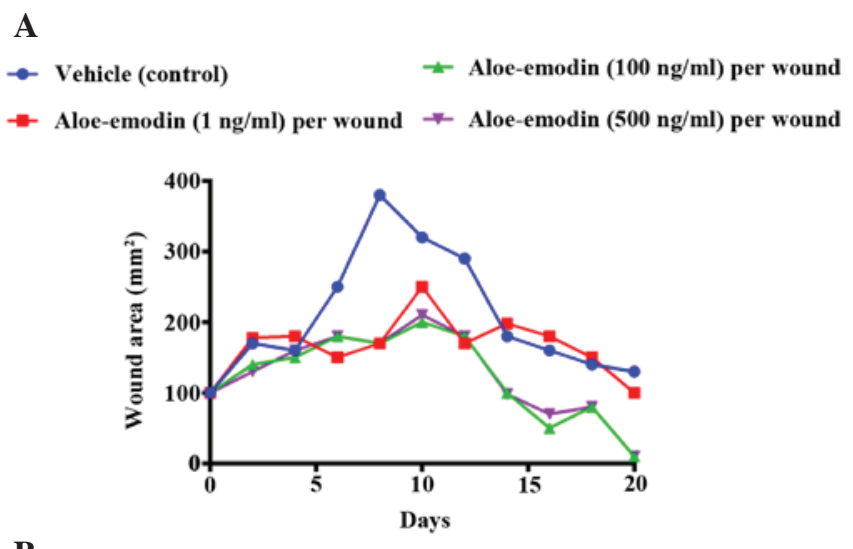

B

$\leftarrow$ Vehicle (control)
- Aloe-emodin $(1 \mathrm{ng} / \mathrm{ml})$ per wound $\rightarrow$ Aloe-emodin $(100 \mathrm{ng} / \mathrm{ml})$ per wound
$\rightarrow$ Aloe-emodin $(500 \mathrm{ng} / \mathrm{ml})$ per wound

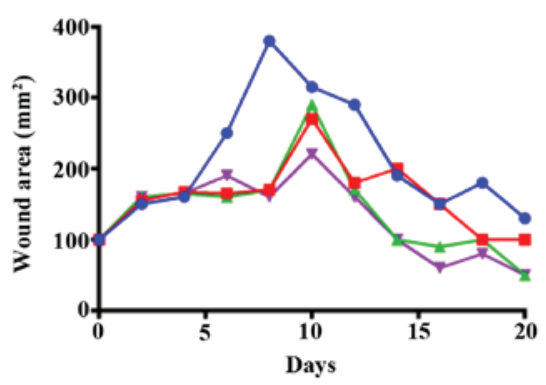

Figure 4. Effects of aloe emodin and resveratrol on burn wound healing in BALB/c mice. (A) Aloe emodin and (B) resveratrol-treated groups. Data are expressed as the mean \pm standard error of the mean of three mice.

Measurement of the levels of IL-1,$M C P-1$ and VEGF in the tissue samples. The levels of IL $1 \beta, \mathrm{MCP}-1$ and VEGF in the exudates of vehicle-treated burn wounded control mice were analysed. The levels of IL-1 $\beta$ increased in a time-dependent 
A

White vaseline (Control)
-Aloe-emodin $(100 \mathrm{ng} / \mathrm{ml})$ per wound

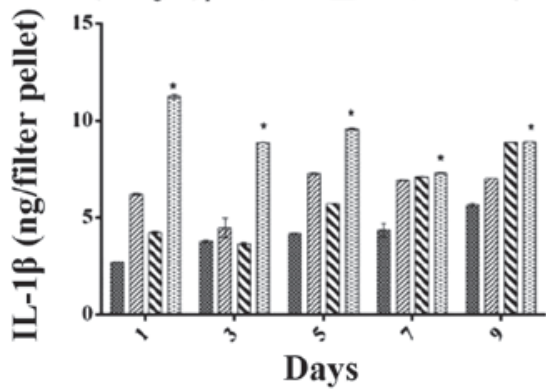

C White vaseline (Control)
$\mathbf{S}+$ Aloe-emodin $(100 \mathrm{ng} / \mathrm{ml})$ per wound
+Aloe-emodin $(1 \mathrm{ng} / \mathrm{ml})$ per wound
+Aloe-emodin $(500 \mathrm{ng} / \mathrm{ml})$ per wound

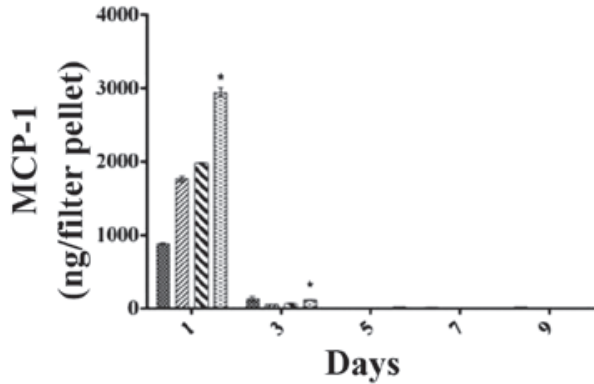

$\mathbf{E}$

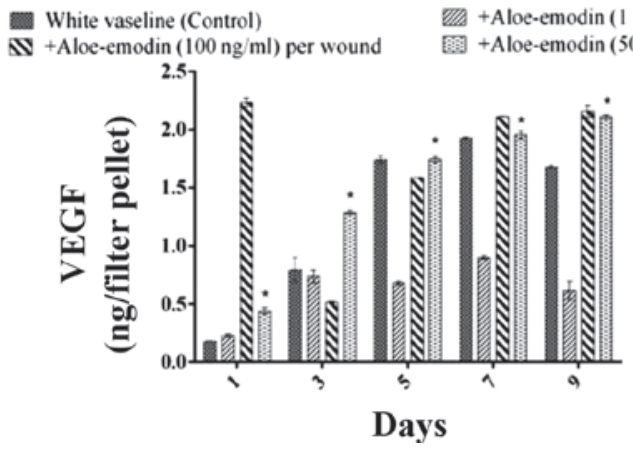

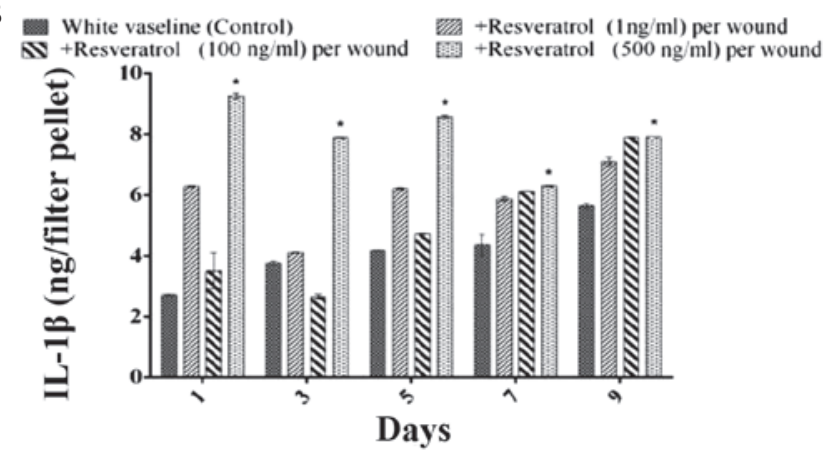

D

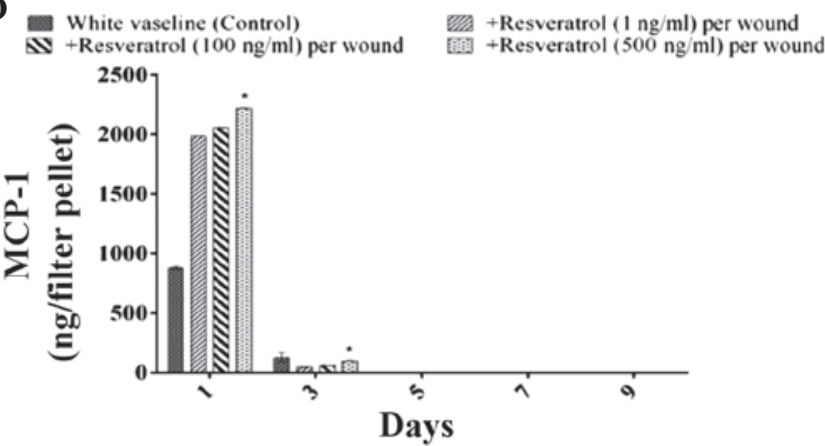

F

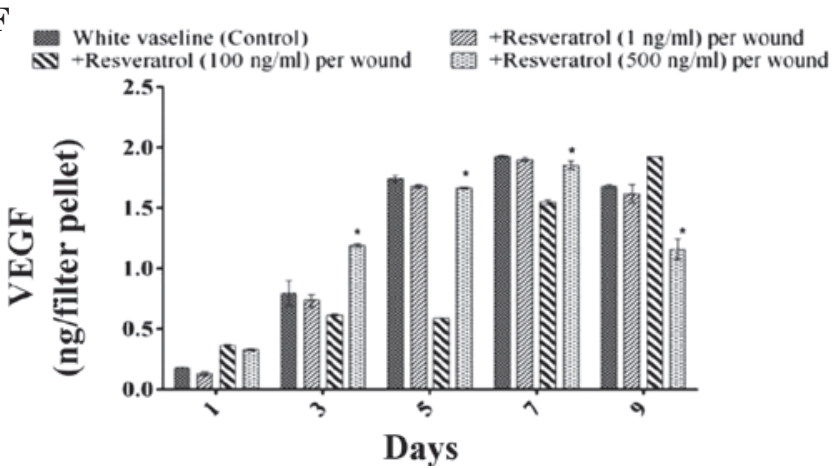

Figure 5. Effects of aloe emodin and resveratrol on the levels of (A and B) IL-1 $\beta$, (C and D) MCP-1 and (E and F) VEGF in the exudates of burn wounded mice. Data are presented as the mean \pm standard error of the mean. $\mathrm{P}<0.05$, vs. control group. VEGF, vascular endothelial growth factor; MCP-1, monocyte chemoattractant protein-1; IL, interleukin.

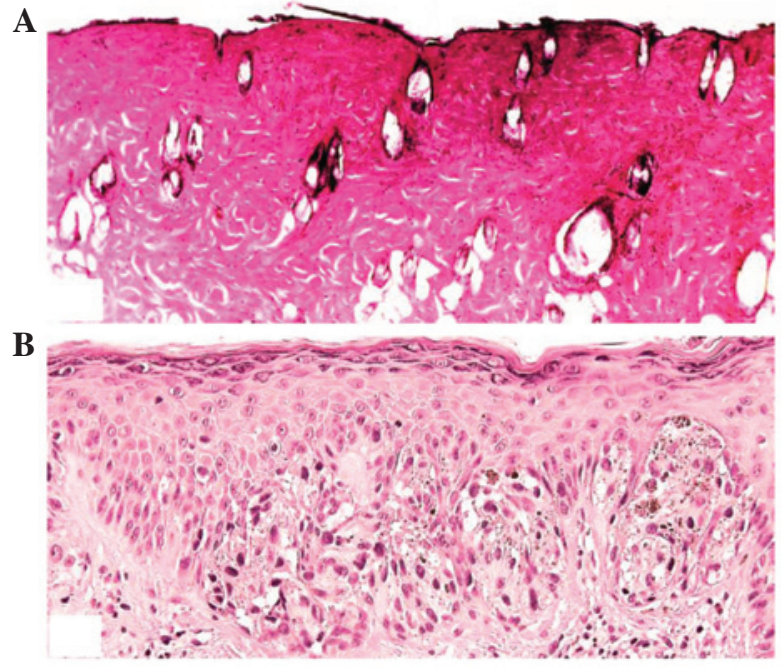

Figure 6. Histological images of the appearance of the skin tissue following burn wounding in the (A) aloe emodin- and (B) resveratrol-treated groups. hematoxylin and eosin staining was performed prior to histological analysis of the tissues. Magnification, x100. manner over the 7 days following wound formation. It is well-known that the production of IL-1 $\beta$ by macrophages is stimulated by lipopolysaccharide. Aloe emodin $(500 \mathrm{ng})$ significantly increased the level of IL-1 $\beta$ on days 1,3,5 and 9, compared with the level observed in the resveratrol (100 ng) and control groups $(\mathrm{P}<0.05)$ (Figs. 5A and $\mathrm{B})$. At a dose of $1 \mathrm{ng}$, aloe emodin also increased the level of IL- $1 \beta$ on day 6 . The migration of polymorphonuclear leukocytes was reduced by aloe emodin and resveratrol $(1,100$ and $500 \mathrm{ng} / \mathrm{ml}) 1$ or 3 days after treatment of the burn. The level of IL-1 $\beta$ production in the exudates of the burn wound area of treated mice increased time dependently 7 days after the tissue was wounded. The MCP-1 level in the exudates of the wound area of control mice reached a maximum level 1 day after burn treatment, and declined 3 days after burn treatment (Figs. 5C and D). The VEGF level in the exudates of the wound area of control mice increased until day 7. The application of asiaticoside at a dose of $100 \mathrm{ng} /$ filter pellet increased the VEGF level on days 1 and 5 compared with that in control mice, and at a dose of $1 \mathrm{ng} / \mathrm{filter}$ pellet, it increased the VEGF level on day 9 (Figs. 5E and F). 
Histopathology. H\&E-stained sections of granulation tissue samples collected on days 4 and 10 following wound formation were examined for cellular infiltration, epithelial regeneration and matrix organization. Granulation tissue was collected on days 4 and 10 for $\mathrm{H} \& \mathrm{E}$ staining Histopathological analysis of the wounds on day 4 indicated increased cellular infiltration in the treated groups, compared with the control group, with no epidermal regeneration observed. After 10 days, the wounds exhibited steady and progressive wound healing in the control group. The eschar had separated, leaving space for the epidermis to grow to complete re-epithelisation. A reasonable level of collagen and numerous inflammatory cells were observed in the corium. The regeneration, stratification and polarity of the epithelial cells were markedly higher in the aloe emodin-treated burn wound, compared with the control. Fig. 6A and B shows the appearance of the mouse burn wound skin tissues at day 10 in the aloe emodin- and resveratrol-treated groups.

\section{Discussion}

Wound healing is a response to injury aimed at reconstructing damaged tissue, and requires the precise coordination of connective tissue repair, re-epithelialization and angiogenesis for generation of new tissue and healing of the wound, increase in fibroblast proliferation and the production of several extracellular matrix proteins and growth factors $(23,24)$. Angiogenesis is required during wound healing, and supplies oxygen and metabolites to new tissue, and disposes of metabolic waste products during wound repair (25). Angiogenesis may also be a key regulatory process in wound healing, as impairment of angiogenesis leads to delayed or unsuccessful wound healing (26).

In the present study, the histological scores demonstrated that the aloe emodin-treated group exhibited higher levels of re-epithelialization and angiogenesis, compared with the control group. Angiogenesis in granulation tissues improves circulation in the wound site, thus providing oxygen and nutrients that are essential for the healing process (27).

It was also observed that aloe emodin concentrations between 10 and $100 \mathrm{ng}$ per wound area The progressive changes in wound area were measured in $\mathrm{mm}^{2}$ by tracing the wound boundaries on a transparent paper every 2 days.

increased the production of VEGF, IL- $1 \beta$ and MCP-1 and the accumulation of macrophages and VEGF-positive cells in the tissue surrounding the burn wound, compared with the control mice. VEGF is a homodimeric glycoprotein, which is highly conserved and shares structural homology with placental growth factor and platelet-derived growth factor (28). Kitano et al (29) demonstrated the suppression of TNF- $\alpha$-induced fibroblast migration and fibronectin deposition in vitro, and that VEGF induced neovascularization, but did not affect cell proliferation or type 1 collagen production. MCP-1 is one of the few chemo attractants expressed by cells, predominantly fibroblasts (30). The recruitment of macrophages occurs due to its upregulation, resulting in the induction of fibrotic reactions through their expression of TNF- $\alpha$., which is a proinflamatory cytokine expressed by epithelial cells and macrophages (29). In the present study, the direct stimulation of VEGF production in $\mathrm{HaCaT}$ keratinocyte cell lines resulted in an increase in the healing action of aloe emodin. Therefore, the results of the present study suggested that aloe emodin promoted angiogenesis during skin wound repair as a result of VEGF stimulation due to an increase in the expression of IL-1 $\beta$ in macrophages. Further experiments are required to elucidate the clinical implication of these findings for burn wound healing.

In conclusion, the present study demonstrated that the application of aloe emodin and resveratrol resulted in a significant increase in healing activity when topically applied on murine burn wounds. These results provide pharmacological evidence supporting the potential use of Aloe vera and Vitis vinifera for burn wound healing.

\section{Acknowledgements}

The authors would like to thank the Department of Plastic of Aesthetic Center, Yantai Yuhuangding Hospital for providing the animals and lab facilities for this study.

\section{References}

1. Reddy KK, Grossman L and Rogers GS: Common complementary and alternative therapies with potential use in dermatologic surgery: risks and benefits. J Am Acad Dermatol 68: e127-e135, 2013.

2. Wild T, Rahbarnia A, Kellner M, Sobotka L and Eberlein T: Basics in nutrition and wound healing. Nutrition 26: 862-866, 2010.

3. Pereira RF, Carvalho A, Gil MH, Mendes A and Bartolo PJ: Influence of Aloe vera on water absorption and enzymatic in vitro degradation of alginate hydrogel films. Carbohydr Polym 98: 311-320, 2013.

4. Eshun K and He Q: Aloe vera: a valuable ingredient for the food, pharmaceutical and cosmetic industries - a review. Crit Rev Food Science Nutri 44: 91-96, 2004.

5. Naqvi S, Ullah MF and Hadi SM: DNA degradation by aqueous extract of Aloe vera in the presence of copper ions. Indian J Biochem Biophys 47: 161-165, 2010.

6. Blumenhal M, Busse NR and Golddberg A: The complete commission E. monographs therapeutic guide to herbal medicine. Integrative Medicines Communications, Boston, MA, pp80-81, 1998.

7. WHO Monographs on Selected Medicinal Plants. Vol 1. World Health Organization, Geneva, Switzerland, 1999.

8. Dat AD, Poon F, Pham KB and Doust J: Aloe vera for treating acute and chronic wounds. Cochrane Database Syst Rev 2: CD008762, 2012.

9. Hamman JH: Composition and applications of Aloe vera Leaf Gel. Molecules 13: 1599-1616, 2008.

10. Im SA, Lee YR, Lee YH, Lee MK, Park YI, Lee S, Kim K and Lee CK: In vivo evidence of the immunomodulatory activity of orally administered Aloe vera gel. Arch Pharm Res 33: 451-456, 2010.

11. Talmadge J, Chavez J, Jacobs L, Munger C, Chinnah T, Chow JT, Williamson D and Yates K: Fractionation of Aloe vera L. inner gel, purification and molecular profiling of activity. Int Immunopharmacol 4: 1757-1773, 2004.

12. Oryan A, Naeini AT, Nikahval B and Gorjian E: Effect of aqueous extract of Aloe vera on experimental cutaneous wound healing in rat. Veterinarski Arhiv 80: 509-522, 2010

13. Nayak BS, Ramdath DD, Marshall JR, Isitor GN, Eversley M, Xue S and Shi J: Wound-healing activity of the skin of the common grape (Vitis Vinifera) variant, Cabernet Sauvignon. Phytother Res 24: 1151-1157, 2010.

14. Hemmati AA, Aghel N, Rashidi I and Gholampur-Aghdami A: Topical grape (Vitis vinifera) seed extract promotes repair of full thickness wound in rabbit. Int Wound J 8: 514-520, 2011.

15. Chan, MMY: Antimicrobial effect of resveratrol on dermatophytes and bacterial pathogens of the skin. Biochem Pharmacol 63:99-104,2002.)

16. Schneider Y, Vincent F, Duranton B, Badolo L, Gossé F, Bergmann C, Seiler N and Raul F: Anti-proliferative effect of resveratrol, a natural component of grapes and wine, on human colonic cancer cells. Cancer Lett 158: 85-91, 2000. 
17. Romero-Pérez AI, Ibern-Gómez M, Lamuela-Raventós RM and de La Torre-Boronat MC: Piceid, the major resveratrol derivative in grape juices. J Agric Food Chem 47: 1533-1536, 1999.

18. Dinarello CA: Immunological and inflammatory functions of the interleukin-1 family. Annu Rev Immunol 27: 519-550, 2009.

19. Park J and Boo YC: Isolation of resveratrol from vitis viniferae caulis and its potent inhibition of human tyrosinase Evidence-Based Complement Alternat Med 2013: 645257, 2013.

20. Lee E and Surh YJ: Induction of apoptosis in HL-60 cells by pungent vanilloids, (6)-gingerol and (6)-paradol. Cancer Lett 134: 163-168, 1998.

21. Mosmann T: Rapid colorimetric assay for cellular growth and survival: Application to proliferation and cytotoxicity assays. J Immunol Methods 65: 55-63, 1983.

22. Maenthaisong R, Chaiyakunapruk N, Niruntraporn S and Kongkaew C: The efficacy of Aloe vera used for burn wound healing: A systematic review. Burns 33:713-718, 2007.

23. Singer AJ and Clark RA: Cutaneous wound healing. N Engl J Med 341: 738-746, 1999.

24. Jettanacheawchankit S, Sasithanasate S, Sangvanich P, Banlunara W and Thunyakitpisal P: Acemannan stimulates gingival fibroblast proliferation; Expressions of keratinocyte growth factor-1, vascular endothelial growth factor and type I collagen; and wound healing. J Pharmacol Sci 109: 525-531, 2009.
25. Inan A, Meral S, Cemile K, Metin E and Cenap D: Effects of Aloe vera on colonic anastomoses of rats. Surg Prac 11: 60-65, 2007.

26. Moon EJ, Lee YM, Lee OH, Lee MJ, Lee SK, Chung MH, Park YI, Sung CK, Choi JS and Kim KW: A novel angiogenic factor derived from Aloe vera gel: Beta-sitosterol, a plant sterol. Angiogenesis 3: 117-123, 1999.

27. Szabo S, Kusstatscher S, Sakoulas G, Sandor Z, Vincze A and Jadus M: Growth factors: New 'endogenous drugs' for ulcer healing. Scand J Gastroenterol Suppl 210: 15-18, 1995.

28. Tischer E, Gospodarowicz D, Mitchell R, Silva M, Schilling J, Lau K, Crisp T, Fiddes JC and Abraham JA: Vascular endothelial growth factor: A new member of the platelet-derived growth factor gene family. Biochem Biophys Res Commun 165: 1198-1206, 1989.

29. Kitano A, Saika S, Yamanaka O, Ikeda K, Okada Y, Shirai K and Reinach PS: Emodin suppression of ocular surface inflammatory reaction. Invest Ophthalmol Vis Sci 48: 5013-5022, 2007.

30. Simpson JE, Newcombe J, Cuzner ML and Woodroofe MN: Expression of monocyte chemoattractant protein-1 and other $\beta$-chemokines by resident glia and inflammatory cells in multiple sclerosis lesions. J Neuroimmunol 84: 238-249, 1998. 